\title{
Medical Cadet Elective to the USA
}

\author{
Lt J I Bisson, RAMC \\ House Physician \\ Queen Alexandra Hospital, Cosham, Portsmouth \\ 2 Lt M Bricknell, RAMC
}

\author{
Medical Cadet \\ University of Southampron
}

The United States of America Armed Forces have their own medical school, the F. Edward Hebert School of Medicine, part of the Uniformed Services University of the Health Sciences, (USUHS). As part of an exchange programme, we were given the opportunity to do a 6 week elective at USUHS in September and October of 1985.

History - USUHS is situated in Bethesda. Maryland, near Washington D.C., and on the same site as the Naval hospital made famous by President Reagan's recent admission. The School of Medicine admitted its first students in 1976. Thirty-two entered then, and it now admits over 100 annually. Unlike other American medical schools, USUHS is a tuition-free institution whose aim is to train medical officers for the Army, Navy, Air Force and the Public Health Service.

Many students have previously served with the military in some capacity, and all have a university degree equivalent; the average age of the students is thus several years higher than that found in the UK. The students are all 2 nd Lieutenants (or equivalent), as in the UK, and are on full pay and allowances. After completing the four year course, their service obligation is seven years after the first internship (Houseman year). Any further specialist training (a residency) does not count toward satisfying the service obligation incurred from participation in the undergraduate course. Therefore, the average time to which a student commits himself is about 11 years after qualification - 1 year's internship, 3 years residency followed by 7 years obligation. The duration of the residency varies according to the speciality.

\section{Curriculum}

The basic curriculum is similar to that of British medical schools, although one year shorter. The first two years are primarily concerned with the basic sciences, and the final two are clinical. The main difference is the military input of the course. Before commencing, all students attend a four week Officers' Orientation Programme in their respective services. Later in the first year, there are lectures on Military Studies, and a 5 week Military Medical Field Studies course. There is no specific military input in the 2 nd and 3 rd years, but the final year includes a 1 week Military Preventive
Medicine course, and a 4 week Military Emergency and Contingency Medicine (MCM) input. We attended this four week course, and followed this by two weeks spent experiencing other aspects of American medicine.

\section{The M.C.M. Course}

During our stay this four week course was more intense than usual due to a 2 day Military Medicine Conference and 2 days for the American students to take national exams in the same period.

The first three weeks were made up of lectures an practicals, and the final week consisted of a field trainin exercise called 'Operation Bushmaster'.

The time was divided as follows:-

\section{Ist WEEK}

B.L.S. = Basic Life Support, an elementary course cardiopulmonary resuscitation, prepared the American Heart Association.

A.C.L.S. = Advanced Cardiac Life Support, an advanced course in cardiac care prepared by the American Heart Association.

\section{2nd WEEK}

A.T.L.S. = Advanced Trauma Life Support, a course prepared by the American College of Surgeons on the initial management of the trauma patient.

\section{3rd WEEK}

Military Medical Conference

National Examinations

\section{4th WEEK}

Briefing for Exercises, Operation Bushmaster

The courses, as stated above, were very intense; each day (including Saturday) started at 7.30 am and finished at $5.00 \mathrm{pm}$.

\section{B.L.S.}

The B.L.S. course was designed to give the student a basic 'first aid' knowledge of how to cope initially with a patient requiring cardiopulmonary resuscitation. Through lectures and practicals, basic skills such as 
mouth to mouth resuscitation and remembering the $A B C$ 's of resuscitation (airways, breathing, circulation) were taught.

\section{A.C.L.S.}

The A.C.L.S. course concerned the medical management of a patient requiring cardiopulmonary resuscitation. The lectures covered the aetiology and natural history of cardiopulmonary problems, and their management. The principles of treatment were taught using specific algorithms which should be followed in particular clinical situations. The algorithm for Bradycardia is shown below.
The main practical of the course was a 6 hour session in the animal laboratory, using anaesthetized dogs to practice the various procedures on. In the first part of the practical, we were expected to treat various ocular and oral injurics which had been surgically produced in the anaesthetized animal, removing external foreign bodies and stitching lacerations. The second part involved life-saving surgical techniques, for example, venous cutdown, cricothyroidectomy, chest tube insertion, peritoneal lavage, pericardiocentesis and open heart massage. At the end of the practical, the dogs, were humancly sacrificed, having becn anaesthetized and painfree throughout the procedure.

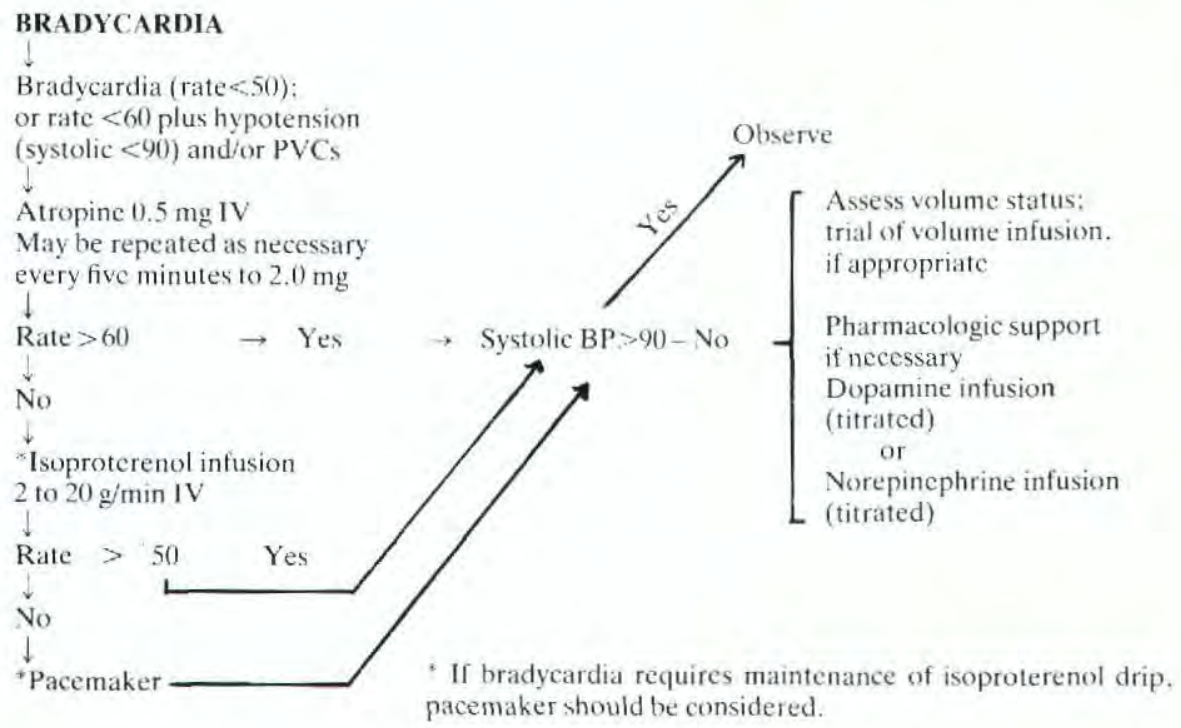

The practicals both reinforced and tested our knowledge gained from the lectures, using special teaching aids. The main aid was 'arrhythmia Annie', a resuscitation manikin attached to an E.C.G. simulator which would change in pattern according to our suggested management.

\section{A.T.L.S.}

The lectures of the A.T.L.S. course took us through the body's anatomy, describing the signs to look for, and how to manage trauma to each area. For example, one session was dedicated to the chest, describing the symptoms and signs of pneumothoraces, pleural effusions, cardiac tamponade etcetera, and the practical procedures required to alleviate the problems.

Practicals with simulated patients took us through the step-by-step management of patients using visual aids such as X-rays of a patient with a pneumothorax before and after chest tube insertion.
Also included in the A.T.L.S. course were lectures on trauma more peculiar to the military, including blast injuries and the effects of nuclear, biological and chemical warfare.

The B.L.S., A.C.L.S and A.T.L.S. were all followed by a multiple choice question paper, a practical assessment and a viva.

\section{Military Medicine Conference}

The first annual USUHS military medicine $\frac{\text { ? }}{3}$ conference occurred on the first two days of our third week. This was a truly international event with speakers from England and Israel supplementing the Americans. Lectures concerned various aspects of military medicine as learned from experiences in Vietnam, Beirut and the Falklands.

\section{Operation Bushmaster}

Following a short bricfing reminding us how to read maps, use a radio and generally how to be a soldier, we 
took a 10 hour coach drive to Fort Devens near Boston, Massachusetts for our exercise. The week contained several combat casualty secnarios, and other training as shown in the week's itinerary below. session. The teaching staff with us would monitor what we did, and respond appropriately, for example, detonating thunderflashes in response to poor light 응 security! Unfortunately, the excrcise endedow

\begin{tabular}{llllll}
\hline & MONDAY & TUESDAY & WEDNESDAY & THURSDAY & FRIDAY \\
\hline $\begin{array}{l}\text { Morning } \\
(07.30-12.00)\end{array}$ & Convoy and Set & Visit to & Move Location, & Helicopter & MASS \\
& up Site & $\begin{array}{l}\text { Combat Support } \\
\text { Hospital }\end{array}$ & Reset-up Site & Training & CASUALTY \\
\hline
\end{tabular}

\begin{tabular}{|c|c|c|c|c|c|}
\hline $\begin{array}{l}\text { Afternoon } \\
(13.00-16.30)\end{array}$ & $\begin{array}{l}\text { Practice Run } \\
\text { Through System }\end{array}$ & $\begin{array}{l}\text { Nuclear Casualty } \\
\text { Exercise }\end{array}$ & $\begin{array}{l}\text { Chemical Casualty } \\
\text { Exercise, CS Gas } \\
\text { Attack and Ex } \\
\text { Filtration }\end{array}$ & $\begin{array}{l}\text { Refugee } \\
\text { Exercise }\end{array}$ & $\begin{array}{l}\text { EXERCISE } \\
\text { (cancelled duc } \\
\text { to Hurricane } \\
\text { 'Gloria') }\end{array}$ \\
\hline
\end{tabular}

Evening

First 'Live'

Combat Casualty

Set up by Night

Plan for

(18.00-21.00)

Exercise

Exercise

Friday

The fact that we had to get up at 5.30 am each morning was compensated for somewhat, by the fact that we slept in GP medium tents on cots (beds), so what sleep we got was of a decent standard. The food provided was centrally cooked by a Medical Support Company, who were also in the field with us. A local engineer battalion provided made-up casualtics for the various scenarios.

A command structure, as shown below, was used for each of the exercises, and the students rotated through prematurely, one day early, as the field was evacuated $\stackrel{\dot{\omega}}{\omega}$ for fear of Hurricane 'Gloria' being too much for eveto our casualty clearing station to cope with.

\section{Conclusions}

Our United States experience was highly education to both of us, and was also very enjoyable. The M.C.I course gave us the opportunity to study aspects

\begin{tabular}{l}
\hline H.Q. Section $\begin{array}{l}\text { Medical Teams } \\
\text { Triage Officer }\end{array}$ \\
Executive Officer
\end{tabular}

different appointments. This meant one could be the Commanding Officer in the morning, a Radio Operator in the afternoon, and a litter (stretcher) bearer in the evening.

The individual exercises lasted for 3-4 hours, with around 15 patients being put through the system in each medicine not covered in our English curriculum, some of which, in particular the B.L.S., A.C.L.S, and $\underset{\omega}{\mathrm{W}}$ A.T.L.S. we feel would benefit all medical students. Other aspects were obviously more specific to ource military bent, and as such, should be invaluable to us in the future. 